The indications prompting thymectomy in Liverpool ${ }^{2 \pi}$ are severe wetakness and incapacity despite anticholinesterase therapy, recurring respiratory infections leading to one or more incidents of myasthenic or cholinergic crisis, and recently married women with hopes of having children.

At New End Hospital over 260 patients with myasthenia gravis have been treated. We offer thymectomy to most patients, as the sooner operation is performed the better the prognosis. ${ }^{32}$ The exceptions are: patients with the purely ocular form of myasthenia, as this seems to be a distinct form of the disease ${ }^{3}$ and the response to thymectomy is disappointing; major contraindication to surgery or anaesthesia such as severe pulmonary or heart disease; elderly patients with mild myasthenia who respond well to drugs; and tumours of the thymus that have not been irradiated.

\section{Preparing Patients for Thymectomy}

The first decision to make is whether a thymic tumour is present or not. Many believe that a tumour should be irradiated before surgery as this improves the already grim prognosis for myasthenic patients with thymic tumours. ${ }^{32}$ Others are unconvinced of the necessity for irradiation before surgery. ${ }^{28}$ Secondly, by trial and error the dose of anticholinergic drugs that will produce the maximum therapeutic response must be determined. Thirdly, pulmonary function studies should be undertaken, and if the vital capacity is seriously reduced a tracheostomy should be performed at the time of thymectomy so that assisted respiration can be provided in the immediate postoperative period, Postoperatively cholinesterase inhibitors are withheld until clinical evidence of their need is apparent, and in this way the serious complication of cholinergic crisis may be averted. $^{33}$ The patient is allowed up by the fifth day and discharged at the end of the second or third week. During the convalescent period the amount of medication, if any, is suitably adjusted.
I am grateful to my surgical colleague $M$. J. Lange for the benefit of his counsel and experience.

\section{References}

1 Simpson, J. A., Proceedings of the Royal Society of Medicine, 1968, $61,757$. Osserman, K. E., Myasthenia Gravis. New York, Grune and Stratton,

3 Parkes, J. D., and McKinna, J. A., Lancet, 1966, 1, 388.

4 Simpson, J. A., Brain, 1958, 81, 112 .

5 Blalock, A., Mason, M. F., Morgan, H. J., and Riven, S. S., Annals of Surgery, 1939, 110, 544.

- Elmqvist, D., Hofmann, W. W., Kugelberg, J., and Quastel, D. M. J., Fournal of Physiology, 1964, 174, 417.

7 Goldstein, G., Lancet, 1968, 2, 119

8 Goldstein, G., and Hofmann, W. W., Clinical and Experimental Immun-

' Kalogy, 1969, 4, 181 . Clinical and Experimental Immunology, 1969, 5, 31.

${ }^{10} \mathrm{Kawanami}$, S., and Mori, R., Clinical and Experimental Immunology, $1972,12,447$.

11 Nakao, K., and Wada, F., Medical fournal of Osaka University, 1968, 19 41.

12 Stricker, E., Thölen, H., Massini, M. A., and Staub, H., fournal of Neurology, Neurosurgery and Psychiatry, 1960, 23, 291.

${ }^{13}$ Lambert, E. H., and Rooke, E. D., in Remote Effects of Cancer on the Nervous System, ed. W. R. Brain, and F. Norris, chapt. 8. New York, Grune and Stratton, 1965

14 Smithers, D. W., Fournal of the Faculty of Radiologists, 1959, 10, 3

15 Nastuk, W. L., Plescia, O. J., and Osserman, K. E., Proceedings of the Society for Experimental Biology and Medicine, 1960, 105, 177

16 Van der Geld, H. R. W., and Strauss, A. J. L., Lancet, 1966, 1, 57

${ }^{17}$ Strauss, A. J. L., et al., Proceedings of the Society for Experimental Biology and Medicine, 1960, 105,184

18 White, R. G., and Marshall, A. H. E., Lancet, 1962, 2, 120.

19 Downes, J. M., Greenwood, B. M., and Wray, S. H., Quarterly fournal of Medicine, 1966, 35, 85 .

20 Simpson, J. A., Scottish Medical fournal, 1960, 5, 419.

21 Lange, M. J., Practitioner, 1966, 196, 448.

21 Lange, M. J., Practitioner, 1966, 196, 448.

22 Keynes, G. L., British fournal of Surgery, 1946, 33, 201

${ }^{23}$ Keynes, G. L., British Medical fournal, 1949, 2, 611.

24 Keynes, G. L., Lancet, 1954, 1, 1197.

${ }_{28}^{25}$ Keynes, G. L., British fournal of Surgery, 1955, 42, 449.

Kreel, I., Osserman, K. E., Genkins, G., and Kark, A. E., Annals of Surgery, 1967, 165, 111 .

27 Edwards, F. R., and Wilson, A., Thorax, 1972, 27, 513.

${ }^{28}$ Papatestas, A. E., Alpert, L. I., Osserman, K. E., Osserman, R. S., and Kark, A. E., American fournal of Medicine, 1971, 50, 405.

29 Perlo, V. P., et al., Neurology, 1966, 16, 431 .

30 Harvey, A. M., Bulletin of the New York Academy of Medicine, 1948, 24, 505.

31 Kark, A. E., personal communication, 1973.

32 Lange, M. J., British fournal of Surgery, 1960, 48, 285

33 Lange, M. J., Proceedings of the Royal Society of Medicine, 1968, 61, 751.

\title{
Delayed Attacks of Malaria in Visitors to the Tropics
}

\author{
PAUL HORSTMANN
}

British Medical fournal, 1973, 3, 440-442

\section{Summary}

Out of 80 Danish college students and their teachers visiting the Middle East, West Pakistan, and India by bus in two four-month journeys during the summer and autumn of 1971, six individuals developed an apparently first attack of vivax malaria within seven to nine months \footnotetext{
Department of Infectious Diseases, Odense University Hospital,

PAUL HORSTMANN, M.D., Chief of Staff
}

after their return to Denmark. No cases of malaria were seen in the group during the journeys. Prophylaxis with chloroquine (Resochin) was strictly observed when visiting the areas in which malaria is endemic.

All cases responded rapidly and completely to a full course of treatment with chloroquine. The most probable cause of the delay of the clinical manifestations is drug prophylaxis, which can prevent a clinical attack but not always eradicate the parasite.

\section{Introduction}

In North Western Europe malaria is probably one of the most 
frequently encountered of the imported diseases. Knowledge of atypical and irregular manifestations of the disease may therefore be of practical clinical importance.

The incubation period of benign tertian malaria is 10-17 days, of falciparum malaria 8-12 days, and of quartan malaria up to 30-40 days. ${ }^{12}$ Thus most travellers who are infected with malaria have their first attack during their stay or shortly after their return from the endemic area. The present report, however, concerns six cases in which the apparently first attack did not occur for many months after their return to Denmark.

The patients were members of a so-called "travelling college." This is an institution in which students accompanied by their teachers go on educational tours in buses as part of their studies. The buses also serve for accommodation. Tours take place several times a year. Each party is composed of about 40 students and five teachers travelling together in five buses with eight students and one teacher in each bus. The first of the journeys related to this report started on 1 May 1971 with return to Denmark on 29 August. The second started on 1 July 1971 and ended on 30 October. The itinerary of the tours was South Eastern Europe, Turkey, Iran, Afghanistan, and Pakistan to India, where they arrived after seven weeks of travelling. After one month in India they returned through the same countries, with a visit to Iraq, and this took about a month.

The health of the subjects during the journeys was good generally with no particular diseases except for some minor cases of diarrhoea. Malaria prophylaxis consisted of chloroquine (Resochin) $500 \mathrm{mg}$ once a week administered on the same day each week by the teacher in the bus. Prophylaxis was started two weeks after the beginning of the journey, when the buses were in Turkey, and lasted until two weeks after the return to Denmark. During March to June 1972 six of the participants had attacks of malaria.

\section{Case Reports}

Case 1.-Man aged 18, student. From 17 to 23 August 1971 this patient had been hospitalized in Pakistan for dysentery. He had been otherwise healthy during the journey. From 16 May 1972 he had lumbar and abdominal pain and daily chills. He was admitted to the surgical ward at the hospital of Odense, and after a few days was transferred to the epidemic department with a suspicion of malaria. Plasmodium vivax was found in the blood. After treatment with chloroquine and primaquine he recovered completely and was discharged after 15 days. Laboratory findings were normal. During his stay the patient informed us that a friend with whom he lodged (case 2) had also become febrile.

Case 2.-Man aged 20, student. During the journey and after his return this patient had been completely healthy until 21 May 1972 , when he suddenly had a chill with fever. On 25 May he was admitted to the epidemic department with a temperature of $41 \cdot 5^{\circ} \mathrm{C}$. $P$. vivax was found in the blood. After treatment with chloroquine and primaquine he recovered completely and left hospital 11 days later.

Case 3.-Man aged 19, bus driver. Apart from one day with fever and an episode of diarrhoea this patient had been in good health during the journey. On 5 May 1972 he had a chill with a rise of temperature to $41^{\circ} \mathrm{C}$. On 31 May he was sent to Dr. S. Fogh, of Copenhagen, who found $P$. vivax in his blood and started treatment with chloroquine and primaquine. This case has been reported elsewhere. $^{3}$

Case 4.-Woman aged 21, student. This patient had been previously healthy and had no illnesses during the journey. In early June 1972 she began to have a remittant fever. On the 29th she was admitted to the County Hospital in Hillerød, medical department F. $P$. vivax was found in the blood and bone marrow and there was some anaemia. Laboratory tests including liver function showed nothing abnormal. She made a complete recovery after treatment with chloroquine and primaquine.

Case 5.-Woman aged 24, teacher. Previously healthy, no illness during journey. In the middle of March 1972-that is seven-and-ahalf months after her return to Denmark-she had repeated attacks of fever with chills. She was treated in hospital with penicillin and streptomycin, after which the temperature became normal. On 22 April she again had high fever and was admitted to the Municipal Hospital, Esbjerg. P. vivax was found in the blood, and treatment with chloroquine (Ercoquin) and primaquine was followed by uneventful recovery. Laboratory tests showed nothing abnormal.

Case 6.-Man aged 21, student teacher. Previously healthy, no illness during journey to India. This patient returned to Denmark on 29 August 1971 . On 29 May 1972 he suddenly had a chill with high temperature, and on 1 June he was admitted to the Municipal Hospital, Esbjerg. $P$. vivax was found in the blood. Treatment with chloroquine and primaquine brought about recovery. Laboratory tests showed neutropenia and a rise in the serum aspartate and alanine transaminase levels. He left the hospital after eight days.

In these six patients the first symptoms of malaria appeared between seven-and-a-half and 10 months after they had left the endemic area. None of the patients had malaria attacks during the journey, and no other cases of malaria were observed in the group. None of them had visited a malarious region since their return. Four of the patients (cases 3, 4, 5, and 6) went on the first tour, while the other two were on the second. These two were members of the same bus group. During the journey this group ran short of chloroquine and had to buy a fresh supply of antimalarials en route. All were cases of vivax malaria. No serious sequelae were noted in any case.

After their return to Denmark only the two patients from Odense (cases 1 and 2) continued to live together, while the rest dispersed to various parts of the country. There was no suspicion of the use of narcotics, and this was also convincingly denied by the participants.

\section{Discussion}

It is well known that relapses of malaria may occur up to two years after the primary attack. Much rarer are cases like those described here, with a greatly protracted incubation period. Yet such cases may be less infrequent in endemic areas and may go unrecognized. In several European countries in which malaria was formerly endemic a sharp rise in the incidence of tertian malaria was frequently seen in early spring. This has especially been noted in Holland, ${ }^{4}$ and the phenomenon considered to be the result of infections contracted during the previous autumn.

Boyd and Kitchen ${ }^{5}$ mentioned a boy aged 14 who after experimental exposure to $P$. vivax developed malaria after a latent period of 204 days. Shute ${ }^{6}$ described several cases of malaria in which the primary attack occurred after a delay up to 9 to 10 months. First relapses frequently occur at about the same time. London et al. ${ }^{7}$ studied 169 cases of delayed primary attacks of vivax malaria of Pacific origin occurring in military personnel during the second world war. They found that the interval between the cessation of malaria suppression therapy and the onset of the delayed primary attacks averaged 41 days but could be longer. Most of the delayed primary attacks were clinically indistinguishable from late relapses but occasionally presented problems of diagnosis-for example, the temperature may be atypical with more or less intermittent fever. The parasite concentration in the peripheral blood was significantly lower in delayed primary cases than in late relapses.

Hernberg $^{8}{ }^{9}$ reported that after the Finnish-Russian war, which ended in 1944, a large malaria outbreak of about 1,000 cases occurred in the spring of 1945 among Finnish soldiers who had served in the Karelian Isthmus. As there were practically no malaria cases in the civil population it was considered likely that the soldiers had acquired malaria during their military service in the summer of 1944 . The latent period until the symptoms of malaria became manifest varied from 9 to 12 months. It was assumed that the malaria plasmodia in a latent stage had survived in the reticuloendothelial tissue.

The causes of such delayed primary attacks of tertian malaria may be varied. Reports by Swellengrebel and de Buck ${ }^{4}$ indicate that infection with very small numbers of parasites (from one or two mosquitoes) can bring about attacks of malaria with a latent period of eight to nine months. Some cases have been reported in which immunity to one strain of malaria parasite has developed after infection with this strain and a full course 
of therapy. In such cases infection with a different strain of the same species of malaria parasite may provoke an attack with a protracted incubation period of several months. Infection with a different species of malaria parasite in such patients resulted in an attack with a normal incubation period. ${ }^{6}$

The most common cause of latency seems to be drug prophylaxis. Shute ${ }^{6}$ described 19 cases of experimental benign tertian malaria in which the incubation period averaged 263 days (range 8-9 months). Such cases have been observed after prophylaxis with quinine, pamaquin, and mepacrine ${ }^{6}$ and chloroquine. ${ }^{7}$

The underlying pathogenic mechanisms of these delayed attacks are still uncertain. In Manson's Tropical Diseases ${ }^{10}$ it is stated that in benign tertian malaria the parasite can be "lying dormant" in the blood stream perhaps for as long as eight months. Shute ${ }^{6}$ thinks that during prophylactic treatment the parasites may be transformed in a resting stage, perhaps in cells of the reticuloendothelial tissue, in which the parasites may survive the cell and later give rise to a generalized infection. Hernberg ${ }^{8} 9$ also assumes that the plasmodia survive in a latent stage in the reticuloendothelial tissue.

It is remarkable that all our cases occurred within about $7 \frac{1}{2}$ to 10 months after the end of exposure. This latent period is nearly identical with the period of delay in Hernberg's cases and in the experimental cases after drug prophylaxis reported by Shute. It is also noteworthy that this interval coincides with the usual time of first relapses. Most probably the latent period is due to an exoerythrocytic resting stage of the parasite, localized in hepatic tissue. Whether the period of 7-10 months of latency is due to characteristics of the parasite or the host is uncertain.

The present series almost bears the character of a biological experiment, in that healthy young persons from a region without malaria were exposed to malaria in an endemic area for a limited period of time. Since six persons out of fewer than 100 contracted malaria the degree of exposure must have been appreciable. Nevertheless, suppressive prophylaxis prevented any primary attack during that period.

Apparently the same drug, chloroquine, that had only a partial effect as a prophylactic was effective in the usual dosage in the fully developed malaria attack in all cases. Obviously the parasites did not become resistant to the drug. Thus the usual suppressive prophylaxis with chloroquine can prevent ordinary primary attacks of benign tertian and other forms of malaria but not always a delayed attack. Such latent cases may be considered as first relapses in which the primary attack has been asymptomatic.
The occurrence of malaria cases with such an excessively prolonged latency is of considerable diagnostic interest. Especially in patients who have never previously shown signs of malaria it is of the utmost importance to be familiar with the possibility of a delayed attack of malaria. Ordinary relapses of malaria are less difficult to diagnose. Cases of malaria with long latency are probably not of great significance in regions where malaria is endemic. However, during the large displacements of military personnel from endemic to non-endemic areas during the second world war the phenomenon seems to have been noted with a much higher frequency than before. In the present era of tourism, in which groups of persons pass a couple of weeks in areas where malaria is endemic and during their stay take suppressive malaria prophylaxis there is good reason to believe that cases of malaria with long latency, such as described above, will become more frequent at our latitudes and perhaps even outnumber cases with an "ordinary" incubation period. This may present diagnostic problems. When an attack of malaria is suspected it may be pertinent to ask not only where the patient was a couple of weeks previously but rather where he sojourned 7 to 10 months or more previously.

Such cases should once more draw the attention of the medical profession to the importance of the maxim of Juvenal, emphasized by Maegraith"1 : Unde venis?"

I wish to thank my colleagues Dr. Gregersen and Dr. Tolstrup, heads of the medical department, Esbjerg Municipal Hospital; Dr. Mogens Iversen, head of the medical department F, Frederiksborg County Hospital, Hillerød; Dr. Toft, Hillerød, and Dr. Sven Fogh, Copenhagen, for kindly informing me of their cases.

\section{References}

1 Maegraith, B., Pathological Processes in Malaria and Blackwater Fever, pp. 4, 12. Oxford, Blackwell, 1948

pp. 4, 12. Oxford, Blackwell, 1948.
2 Russell, P. F., et al., Practical Malariology, p. 284. Philadelphia, Saunders, 1946.
ogh, S., Ugeskrift for Lager, 1972, 134, 2046.

3 Fogh, S., Ugeskrift for Lager, 1972, 134, 2046.

- Swellengrebel, N. H., and de Buck, A. (1938). Quoted by Shute. ${ }^{\circ}$ Boyd, M. F., and Kitchen, S. F., American fournal of Tropical Medicine, $1938,18,729$.

- Shute, P. G., Transactions of the Royal Society of Tropical Medicine and Hygiene, 1946, 40, 189.

' London, Irving M., et al., New England Fournal of Medicine, 1946, 235, 406.

${ }^{8}$ Hernberg, C. A., Nordisk Medicin, 1946, 30, 1369.

- Hernberg, C. A., Nordisk Medicin, 1946, 31, 1961.

${ }^{10}$ Manson-Bahr, P., and Wilcocks, C., Manson's Tropical Diseases, 16th edn., p. 61. London, Baillère, Tindall and Cassel, 1966

${ }_{11}$ Maegraith, B., Lancet, 1962, 1, 401. 